\title{
Presença e visibilidade da literatura hispanófona em quatro revistas brasileiras de biblioteconomia, documentação e ciência da informação: análise de citação
}

\author{
Maria de Jesus Nascimento \\ Doutora em ciência da informação; professora da Udesc. \\ E-mail: jesusnascimento@hotmail.com
}

\begin{abstract}
RESUMO
Análise de citação de quatro revistas brasileiras de biblioteconomia, documentação e ciência de informação no período de 1990 a 2006, visando a detectar a presença da literatura da área publicada e citada em espanhol. Destaca a revista Ciência da Informação como a mais produtiva de artigos e citações e a Espanha responsável pelo maior número de artigos publicado. Pelo pouco uso da literatura espanófona como base para a produção do conhecimento brasileiro e pelo elevado número de artigos de autoria individual, conclui-se que não há equipe de pesquisadores trabalhando em cooperação na América do Sul.
\end{abstract}

\section{PALAVRAS-CHAVE}

Ciência da informação. Informação no Mercosul. Citação em espanhol. Periódicos de biblioteconomia.

\section{Presence and visibility of Spanish literature in four Brazilian library journals, documentation and information science: analysis of citation}

\section{ABSTRACT}

Citations analysis of four library and information science Brazilian journals in the period of 1990 to 2006. The main objective is to point out the Spanish literature published and cited in the four Brazilians journals. "Ciência da Informação" published and cited the majority of Spanish language works. By the few use of Spanish literature by Brazilian authors and by the high number of individual authors we conclude that there is no research group working in collaboration in the South America.

\section{KEYWORD}

Information science. Information in Mercosul. Spanish citation. Citation analysis. Library and information science journals.

\section{INTRODUÇÃO}

A comunicação dos resultados de pesquisa é uma prática que remonta à Grécia clássica, quando a atividade dos grandes filósofos era feita oralmente. Embora não se objetive fazer uma descrição cronológica de fatos históricos, salientam-se algumas afirmações e definições tradicionais, consagradas na literatura da área, para melhor enfatizar a abordagem teórica que embasa o estudo em questão.

Segundo Sabatini (1999), a palavra "academia" deriva do nome de um bosque de oliveiras onde Platão costumava encontrar-se para discutir com seus discípulos. Mas foi com o desenvolvimento da ciência no período tardio da Renascença Italiana (início do séc XVII) que os cientistas sentiram a necessidade de se organizarem em academias. A primeira que a história registra e ainda existe é a Accademia dei Linces, fundada em Roma em 1603.

Todavia, em períodos anteriores, em outros países da Europa já existiam academias, como a Academia de Matemática de Madrid, que data de 1582. Para López Piñero, Navarro e Portela (1989), foi a partir dessas academias que os contatos entre os cientistas se tornaram mais freqüentes, e a correspondência que mantiveram entre 1620 e 1680 ocupou lugar de destaque como veículo de comunicação da ciência internacional.

Os parâmetros da ciência e os cientistas vêem mudando ao longo dos anos, adquirindo novos valores, crescendo quantitativa e qualitativamente, passando do amadorismo ao profissionalismo mais sofisticado, organizando-se em grupos de especialistas independentemente de barreiras geográficas e políticas.

Para Schwartzman (1979, p. 2), "o conhecimento científico pode ser entendido, abstratamente, como um conjunto de informações ou dados cujo valor independe dos homens que o produziram". Tal afirmativa reitera a idéia de que o conhecimento científico é um bem universal, embora a ciência seja o resultado do trabalho de uma comunidade de pessoas bem-formadas e no auge da inteligência e da capacidade criativa.

Embora a atividade científica, por questões de sigilo e prioridades, possa seguir uma orientação nacionalista, muitas vezes é difícil determinar a "origem nacional" de determinado 
avanço científico, tendo em vista o êxodo de cientistas, os sistemas de cooperações multinacionais e a publicação de artigos em periódicos internacionais.

Em geral os países subdesenvolvidos e em vias de desenvolvimento tendem a seguir os padrões da ciência do primeiro mundo. "Daí o fato de que a ciência que se desenvolve na periferia seja muitas vezes percebida como 'alienada', desligada das necessidades práticas nacionais" (SCHWARTZMAN, 1979, p.16). O autor, que considera as "fronteiras da ciência" como um universo de possibilidades, defende a preservação e o desenvolvimento pleno da comunidade científica nacional, desde que pautada em critérios de excelência.

Internacional ou não, o fato é que, no dizer de López Piñero, Navarro e Portela (1989, p. 49), um dos motores da ciência moderna foi precisamente o intercâmbio de informações que proliferou na Europa não só com as academias, mas também com as tertúlias científicas, onde se reuniam eruditos que discutiam periodicamente os problemas da nova ciência. A partir de então surgiram os gabinetes e bibliotecas para lhes servir de apoio.

Para reforçar a idéia baconiana de que a ciência era universal, os resultados das pesquisas científicas começaram a ser publicados em formato mais rápido que o livro, meio até então utilizado, porém de circulação restrita e de publicação lenta. Os tipos móveis de Gutenberg foram fator fundamental para facilitar e agilizar a publicação das cartas que os cientistas trocavam entre si para discutir os resultados de suas pesquisas, correspondências essas que constituíam o então chamado "Colégio Invisível".

A sistematização e a divulgação periódica dessas cartas deu origem às primeiras revistas científicas Journal des Savants (jornal dos sábios), criado na França em 1662, e Philosophical Transactions, da Royal Society de Londres, que permanece viva e circula até hoje (LÓPEZ PINERO; NAVARRO; PORTELA, 1989, p. 51).

Segundo Muñoz (2004), a ciência é como uma empresa da própria mente humana da qual cabe ao cientista criar o conhecimento e dá-lo a conhecer à comunidade científica por meio das publicações; e nesse aspecto as revistas oferecem grandes oportunidades para comunicar e difundir a ciência.

Embora a tradição científica brasileira não esteja no mesmo patamar dos países desenvolvidos, é bem maior do que em geral se imagina, se for considerado o trabalho dos pioneiros descrito por Azevedo (1955), citado por SCHWARTZMAN (1979): foram cientistas estrangeiros, viajantes que desbravaram nossa flora, fauna, solo e céu, e muito contribuíram para o desenvolvimento das ciências biológicas, zoologia, químicas, geologia, astronomia e meteorologia, mas não formaram discípulos, não criaram comunidades acadêmicas nem deixaram uma tradição de continuidade do trabalho científico.

A tradição da pesquisa estruturada inicia-se com Osvaldo Cruz, considerado um dos fundadores da ciência no Brasil, criador do instituto que leva o seu nome, hoje Fundação Osvaldo Cruz (Fiocruz), instituição que em 1910 publicou a primeira revista científica brasileira, Memórias do Instituto Osvaldo Cruz.

Para Azevedo (1963, p. 423), "a atitude dos brasileiros em geral em relação à ciência é uma atitude de admiração pelos avanços da ciência, mas de indiferença e desinteresse pelo trabalho científico", em decorrência das raízes étnicas e do tipo de formação determinado exclusivamente pela atmosfera cultural e pelas condições de vida. Já para Morel (1979, p. 24), as características do sistema científico brasileiro não são provenientes de fatores étnicos nem culturais, mas de fatores econômicos e sociais.

Independentemente do argumento que se use para tentar justificar a morosidade do desenvolvimento científico brasileiro, o certo é que, em conseqüência e por razões de barreira lingüística, o periódico científico nacional está muito longe de alcançar o nível de visibilidade dos periódicos dos países centrais, não obstante na área de biblioteconomia sua posição seja privilegiada em relação aos demais países latino-americanos.

De acordo com Urbizágastegui Alvarado (1999), dentre os 11 países latino-americanos cujas revistas da área de biblioteconomia e ciência da informação estão indexadas nas bases de dados Online Computer Library Center (OCLC), Information Abstract (ISA), Library Literature (LL), Library and Information Science (LISA), Información y Bibliotecología Latinoamericana (INFOBILA) e no Diretório Internacional de Periódicos URICH, o Brasil sobressai com o maior número de revistas: calculam-se mais de $31 \%$ do total. O estudo também tabula as revistas eletrônicas de seis países, e também aí o Brasil segue ocupando o primeiro lugar.

Embora os dados de Urbizágastegui Alvarado careçam de atualização, pois não incluem seis revistas eletrônicas brasileiras, das analisadas por Nascimento e Boso (2007), dentre as quais duas da década de 90 e quatro editadas a partir do ano 2000, as últimas, portanto, não poderiam ser incluídas em seu estudo, e seguramente o panorama nos demais países latino-americanos também tenha mudado, permanecem válidas as conclusões de Urbizágastegui Alvarado (1999, p.164) de que os

[...] esforços deveriam ser dirigidos mais para os agentes e não necessariamente para a manifestação das práticas dos capitais culturais que são as revistas, já que estas são apenas canais para veicular as práticas desses agentes.

O autor também aponta a necessidade de melhorar a edição das revistas, sua adequação às normas internacionais e a indexação em bases de dados.

Segundo Arenas (2000), o Brasil é o país latino-americano com maior número de revistas na área de biblioteconomia, responsável por 53,6\% dos artigos indexados nas bases de dados Information Science abstracts, Library and Information Science abstract e Library literature. 
No seu levantamento da imprensa periódica no Brasil na área de biblioteconomia, Castro (2006) cita a publicação do Boletim Informativo FEBAB e do Boletim do IBBD, posteriormente IBBD Notícias Diversas, anteriores aos anos 70. Mas a primeira publicação considerada revista científica foi criada pelo antigo Instituto Brasileiro de Bibliografia e Documentação (IBBD), que em 1976 passaria a denominar-se Instituto Brasileiro de Informação em Ciência e Tecnologia (Ibict) e que edita até hoje a revista Ciência da Informação.

Desde então, as publicações periódicas brasileiras na área vêm crescendo, não apenas o número de novas revistas, editadas por universidades e associações de classe, mas também na qualidade de seus artigos, padronização e periodicidade da publicação e, mais recentemente, no formato de apresentação de publicações eletrônicas, que nos últimos anos vêm tendo considerável expansão.

Le Coadic (1996) se refere às revistas científicas como uma das estruturas que visam a dar status científico e social à ciência da informação e as agrupa em cinco continentes e ilhas: o continente núcleo, o continente do papel, o continente eletrônico, o continente periférico, a ilha francófona, a ilha lusófona e a ilhota cultural. Le Coadic (1996, p. 112) especifica:

A ilha lusófona: Ciência da Informação; Revista de Biblioteconomia de Brasília; Revista Brasileira de Biblioteconomia e Documentação; Revista da Escola de Biblioteconomia da Universidade Federal de Minas Gerais; Cadernos de Biblioteconomia, Arquivística e Documentação; Bibliotecas, Arquivos e Museus.

Mueller (1996) faz um levantamento dos principais periódicos da área e identifica 32 títulos, muitos dos quais não são exclusivos da área, não estão devidamente padronizados, não têm periodicidade regular ou até foram desativados. A autora considerou como pertinentes e ativos, na época de seu estudo, apenas quatro títulos: Ciência da Informação; Revista de Biblioteconomia de Brasília; Informação Eु Sociedade: Estudos; Revista da Escola de Biblioteconomia da Universidade Federal de Minas Gerais, que atualmente se denomina Perspectivas em Ciência da Informação; Revista Brasileira de Biblioteconomia e Documentação. A autora também incluiu em seu estudo a Revista de Biblioteconomia e Comunicação da Universidade Federal do Rio Grande do Sul e a Transinformação.

Nos anos 90, as revistas brasileiras da área se limitavam a prestigiar a produção do conhecimento endógeno; algumas em suas regras editoriais exigiam artigos somente em língua portuguesa. Ao contrário, a Revista de Biblioteconomia de Brasília e a Ciência da Informação sempre foram receptivas à comunidade internacional.

Para Mueller e Pecegueiro (2001), a revista Ciência da Informação é um dos periódicos de maior credibilidade na área. E, como comprova Nascimento (1999), desde os primeiros números citava, e inclusive publicava, na íntegra, artigos em inglês. Posteriormente passou a publicar também em espanhol, como destaca Miranda (1998), "[...] legitimados pelos objetivos integracionalistas do Mercosul”.

De uma forma ou de outra, sendo a ciência um bem universal ou patriota, a atividade científica brasileira resultante de fatores sociais e econômicos, étnicos e culturais, ou não, estando as revistas abertas à comunidade científica internacional, ou, ao contrário, restritas às fronteiras nacionais, o fato é que, tradicionalmente, o Brasil pesquisa conhecimento na literatura internacional, preferencialmente na divulgada em inglês, idioma oficial da comunicação científica internacional. Mas como observa Nascimento $(1999$, p. 5):

Com a participação do Brasil no Mercado Comum do Sul (Mercosul), único país latino-americano de língua portuguesa, necessário se faz a utilização do espanhol como segunda língua, para facilitar as negociações no mercado; o processo de comunicação científica; e o intercâmbio de informações.

Criado em 1991 pelo Tratado de Assunção, o Mercosul é um acordo de livre comércio que tem entre seus objetivos consolidar a democracia, a economia e a integração dos países-membro. Inicialmente faziam parte do bloco Brasil, Argentina Paraguai e Uruguai, posteriormente, em 1996, Chile e Bolívia passam a fazer parte como membros associados. (SENA CORREA, 2003).

De acordo com Neves e Morosini (1995), no contexto do paradigma integracionalista latino-americano, a universidade é parte ativa do processo. Portanto, espera-se que a cooperação universitária ocorra de fato e se honrem os acordos bilaterais que objetivam intensificar o intercâmbio científico e cultural, principalmente os que pregam o desenvolvimento de projetos de pesquisa e a publicação de trabalhos em cooperação.

Para se adequar à sociedade da informação e consolidar a integração na região, o Mercosul deve incrementar as políticas de informação, o intercâmbio de informações e a utilização de fontes de informações geradas na região, reconhecendo e utilizando tanto o espanhol quanto o português na comunicação científica.

No mundo globalizado não há espaço para os monolíngües e tal preocupação está explicitada nas decisões da Cumbre Mundial sobre la Sociedad de la Información, realizada em Genebra em 2003, com vistas ao desenvolvimento de ações no Mercosul, que segundo Menezes (2004), recomenda o plurilingüismo e o acesso universal ao ciberespaço e a promoção do domínio público da informação.

Nascimento sugere ainda que, para superar a etnocentria cultural, científica e tecnológica do Brasil em relação à América, além de acordos comerciais, é imprescindível incentivar o entrosamento da comunidade científica, priorizando a pesquisa em colaboração, o intercâmbio de informações, a publicação de 
artigos em co-autoria com pesquisadores hispanoparlantes e o incremento das citações à literatura hispanófona nas revistas brasileiras e vice-versa.

Com tal preocupação em face da carência do setor da informação documentária no âmbito latino-americano, Nascimento (1999) examinou a presença da literatura de língua espanhola utilizada como base para a produção do conhecimento divulgado nas principais revistas brasileiras da área

[...] com maior repercussão na comunidade científica e acadêmica, que divulgam trabalhos de reconhecida qualidade, que representam organismos e instituições de destaque nacional e estão direta ou indiretamente ligadas às atividades de ensino e pesquisa.

As revistas analisadas por Nascimento (1999) foram Ciência da Informação (editada pelo IBICT desde 1972), Revista de Brasileira de Biblioteconomia e Documentação (RBBD, editada pela Febab desde 1972, substituindo o antigo Boletim Febab, fundado em 1960), Perspectivas em Ciência da Informação (editada pela UFMG a partir de 1996, substituindo a Revista da Escola de Biblioteconomia da UFMG, fundada em 1972), Revista de Biblioteconomia de Brasília (RBBR, de 1973), Transinformação (1989) e Informação Eु Sociedade: Estudos (editada pela UFPb desde 1991). Os resultados do estudo foram apresentados em dois períodos: antes do Mercosul (de 1983 a 1990) e no Mercosul (de 1991 a 1998).

O referido estudo concluiu que geralmente as revistas brasileiras dessa área são monolíngües e poucos são os autores brasileiros que fazem citação em espanhol. Foi constatada também a tendência de se publicarem artigos individuais, havendo quase inexistência de trabalhos de autoria múltipla, tanto no que diz respeito aos artigos citantes quanto aos trabalhos citados, o que confirma a falta de grupos consolidados de pesquisa na região.

Nascimento (1999) observa ainda que o Mercosul pode ter influenciado, levando à mudança de atitude de algumas revistas, mas a desejada troca de informações ainda não está refletida na literatura, razão pela qual sugere que se realize estudo dessa natureza em períodos posteriores, para averiguar o incremento, ou não, da integração entre os pesquisadores latino-americanos. Portanto, dá-se continuidade ao estudo com o intuito de comparar os dados e constatar as possíveis mudanças de atitudes dos atores e dos canais que divulgam a produção gerada pela comunidade científica da área em questão.

\section{METODOLOGIA}

Trata-se de um estudo bibliométrico, ou seja, de um modelo de análise quantitativa e descritiva, precisamente de uma análise de citação da literatura de biblioteconomia, documentação e ciência da informação publicada e/ou citada nas revistas brasileiras da área.
O material utilizado consta de artigos, citações e/ou referências, em espanhol, de quatro das revistas analisadas anteriormente por Nascimento (1999), que têm, ou pelo menos tinham sua versão impressa, apresentam comitês editoriais e, embora algumas saiam com atraso, continuam sendo editadas regularmente, tendo sido excluídas as que, em algum momento, apresentaram falhas em sua periodicidade ou dificuldade de acesso. Portanto, analisamse Ciência de Informação, Perspectivas em Ciência da Informação, Transinformação, e Informação $\mathbb{E}$ Sociedade: Estudos. Na classificação da Coordenação de Aperfeiçoamento de Pessoal de Nível Superior (Capes), conforme Brasil (2007), todas são Qualis A.

Tendo em vista a falta de padronização e a diversidade terminológica das seções que constam nos sumários das revistas, para efeito deste estudo foram considerados como artigos todos os trabalhos (artigos de revisão, estudos, memórias científicas, comunicações, pontos de vista, relatos de experiência, relatos de pesquisa etc.) que apresentam resumo, palavras-chave e referências ou notas bibliográficas. Foram excluídas as apresentações, editoriais, notas de livros, resenhas ou recensões e os resumos de teses.

O período analisado é bastante abrangente e representativo, pois inclui oito anos, de 1999 a 2006, para constatar a taxa de crescimento da publicação de artigos em espanhol nas revistas nacionais e caracterizar os padrões de citações feitos à literatura em espanhol pelos autores brasileiros. O tempo foi determinado tendo em vista fazer uma comparação da "presença" da literatura hispanófona nas revistas brasileiras com os períodos anteriores analisados por Nascimento (1999): oito anos antes do Mercosul e oito imediatamente posteriores à criação do Mercosul.

Constatar a "presença" ou a "visibilidade" de determinada literatura em uma produção científica específica, tanto registrada em uma base de dados quanto em periódicos científicos, é uma forma de utilizar procedimentos bibliométricos para avaliar área específica do conhecimento em determinado contexto, no caso a área de biblioteconomia, documentação e ciência da informação no âmbito da América Latina e em especial do Mercosul.

Pritchard (1969), em substituição à expressão bibliografia estatística, utilizou, pela primeira vez, o termo bibliometria, para definir a "aplicação de modelos matemáticos e estatísticos aos livros e outros meios de comunicação escrita". Inúmeros autores têm definido a bibliometria como um método científico da ciência da informação. De acordo com Ferreiro (1993), a bibliometria consiste na aplicação de métodos estatísticos e matemáticos para definir os processos de comunicação escrita e a natureza e desenvolvimento das disciplinas científicas. E "presença" é conceituada como uma parte desconhecida da produção ou literatura científica que se identifica em coleção ou base de dados.

A bibliometria possibilita situar a produção científica de um país em relação ao mundo, de uma instituição em relação a seu país e até mesmo de um cientista em relação à comunidade. 
Inúmeros são os estudos que utilizam a técnica da bibliometria denominada análise de citação para quantificar os processos de comunicação escrita, principalmente publicada em periódicos científicos. Portanto, utiliza-se aqui o termo "presença" como a existência, estado ou comportamento da literatura hispanófona, nas revistas brasileiras, até então não analisada.

Além da pesquisa de Nascimento (1999), nesse enfoque, paralelamente, Nascimento e Boso (2007) desenvolveram outro estudo, analisando exclusivamente as revistas brasileiras eletrônicas, no período de 2005 a 2006, cujos dados podem, até certo ponto, ser comparados com os resultados desta pesquisa.

\section{RESULTADOS}

Tendo em vista que, entre os problemas da divulgação do conhecimento, a barreira lingüistica é um dos fatores que afetam diretamente a prática da citação e com o objetivo de examinar os efeitos do Mercosul nas atividades informacionais, analisase a presença da literatura de biblioteconomia, documentação e ciência da informação, divulgada e citada, em espanhol, nas revistas brasileiras da área, no período de oito anos, precisamente de 1999 a 2006, comparando os resultados com os do estudo anterior de Nascimento (1999), que analisou os períodos antes do Mercosul, de 1983 a 1990, e no pós-Mercosul, de 1991 a 1998.

Como não é objetivo deste estudo avaliar os periódicos brasileiros da área, são apenas mencionadas algumas de suas características para tentar explicar os resultados que, de certo modo, refletem, principalmente, a sua periodicidade e sua padronização.

Em alguns casos, as revistas analisadas deixam a desejar quanto à regularidade e à pontualidade da publicação. Quanto à normalização, na apresentação das referências já melhoraram consideravelmente em relação ao estudo anterior, em que apresentavam muitas falhas, mas ainda seguem publicando artigos sem referências.

Para se ter uma visão do todo e para efeito de comparação dos dados, foi levantado o total de artigos e citações nos diferentes idiomas. $\mathrm{O}$ universo se constitui de 805 artigos e de 17.270 citações, como se pode visualizar na tabela 1. Dos artigos, 13 não produziram nenhuma citação, um porque não foi possível o acesso ao texto completo, e os demais porque não traziam as referências; dentre eles, dois continham apenas algumas notas.

Tendo em vista o objetivo da pesquisa, faz-se a análise de citação apenas dos 281 artigos citantes e respectivas 1.235 citações ou referências em espanhol, das notas de rodapé e das referências ao final do artigo, observando-se as seguintes variáveis: local e data de publicação e tipo de documento citado.

Quanto ao total de artigos publicados, a revista quadrimestral Ciência da Informação publicou uma média de 12,5 artigos por número e
37,5 por ano, sendo a maior produtora, responsável por 37,3\% do total de artigos e por 70,2\% dos divulgados em espanhol.

Em segundo lugar, a revista Informação e Sociedade: Estudos, com periodicidade semestral, publicou em média 11,8 artigos por número e 23,5 por ano, tendo publicado 23,5\% do total, embora fique em terceiro lugar na divulgação de artigos em espanhol.

A revista Transinformação torna-se quadrimestral a partir de 2003, ano em que editou também um número especial, publicou em média 7,2 artigos por revista e 21,2 por ano. Embora responda por apenas 21,1\% do total de artigos, ficou em segundo lugar, com $21 \%$ dos 57 artigos em espanhol.

Tabela 1

Idioma dos artigos publicados por revista de 1999 a 2006

\begin{tabular}{l|r|r|r|r|r|r}
\hline Revistas & Ci. Inf. & Inf.\&Soc. & Perspect. & Transinf. & Total & $\%$ \\
\hline Português & 251 & 184 & 146 & 156 & 737 & 91,6 \\
Espanhol & 40 & 5 & - & 12 & 57 & 7,1 \\
Inglês & 8 & - & - & 2 & 10 & 1,2 \\
Francês & 1 & - & - & & 1 & 0,1 \\
\hline Total & $\mathbf{3 0 0}$ & $\mathbf{1 8 9}$ & $\mathbf{1 4 6}$ & $\mathbf{1 7 0}$ & $\mathbf{8 0 5}$ & $\mathbf{1 0 0}$ \\
\hline$\%$ & $\mathbf{3 7 , 3}$ & $\mathbf{2 3 , 5}$ & $\mathbf{1 8 , 1}$ & $\mathbf{2 1 , 1}$ & $\mathbf{1 0 0}$ & - \\
\hline
\end{tabular}

Fonte: dados da pesquisa

Além dos dois artigos em inglês, constatou-se, na Transinformação, a tradução para o português de dois artigos do inglês e um do espanhol. Considerando a semelhança lingüística e a necessidade de integração e intercâmbio de informação entre a comunidade científica latino-americana, em particular do Mercosul, o que indubitavelmente requer, no mínimo, conhecimento mútuo do português e do espanhol, não justifica traduzir do espanhol para o português nem vice-versa.

A revista Perspectiva em Ciência da Informação, semestral, que também publicou dois números especiais, com média de 8,1 artigos por revista e 18,5 ao ano, é a menos expressiva de todas, tanto no número de artigos, que responde por apenas $18,1 \%$ do total, quanto pelo fato de não ter divulgado nenhum artigo em espanhol e em nenhum outro idioma. Publicou apenas um artigo traduzido do inglês e um em português de autor de instituição estrangeira. A maioria dos autores é da própria UFMG, portanto é a mais endógena de todas as revistas.

É óbvio que, por se tratar de revistas brasileiras, a quase totalidade dos artigos $(91,6 \%)$ tenha sido divulgado em português, 7,1\% em espanhol, apenas 1,\% em inglês e em francês o insignificante percentual de $0,1 \%$.

Comparando tais dados aos da pesquisa anterior de Nascimento (1999), pode-se afirmar que não houve mudança significativa na atitude das revistas e da comunidade científica em relação ao uso do idioma espanhol. Houve apenas aumento de 3,8\% de artigos publicados em espanhol no período de 1991 a 1998 
para 7,1\% no período de 1999 a 2006. Já com os artigos em inglês ocorreu o contrário: no primeiro período representavam $1,5 \%$ e caíram para $1,2 \%$. Esse fato se explica por razões de afinidade lingüística entre idiomas de origem latina, em parte pela proximidade geográfica com os demais países da região e por sutil preocupação com o ideal integracionista do Mercosul.

Os índices de publicação de artigos, por idioma, assemelhamse aos resultados encontrados por Pinto, Rodríguez Barquín e Moreiro Gonzáles (2006) na análise da revista Ciência da Informação no período de 1995 a 2003, que foram: $225 \mathrm{em}$ português, 19 em espanhol e 4 em inglês, o que corresponde respectivamente a $90,7 \%, 7,7 \%$ e $1,6 \%$.

Os 57 artigos em espanhol foram distribuídos na tabela 2 por ordem cronológica de ano de publicação. Os anos mais produtivos foram 2003 e 2004, com 21,1\%; o menor índice foi em 2005, com apenas 3,5\% dos artigos. Os percentuais apontam crescimento desordenado: embora em maiores proporções que os períodos analisados anteriormente por Nascimento (1999), permanecem inexpressivos.

Tabela 2

\section{Artigos divulgados em espanhol}

\begin{tabular}{r|r|r|r|r|r|r}
\hline \multicolumn{1}{|c|}{ ANO DE } & \multicolumn{3}{|c|}{ REVISTAS } & \multirow{2}{*}{ TOTAL } & \multicolumn{1}{c}{$\%$} \\
\cline { 2 - 5 } PUBLICAÇÃo & Ci. Inf. & Inf. Soc. & Perspect. & Transinf. & & \\
\hline 1999 & 3 & - & - & 4 & 7 & 12,2 \\
2000 & 3 & 1 & - & - & 4 & 7,0 \\
2001 & 2 & - & - & 1 & 3 & 5,2 \\
2002 & 5 & 1 & - & - & 6 & 10,5 \\
2003 & 5 & - & - & 7 & 12 & 21,1 \\
2004 & 11 & 1 & - & - & 12 & 21,1 \\
2005 & 2 & - & - & - & 2 & 3,5 \\
2006 & 9 & 2 & - & - & 11 & 19,3 \\
\hline TOTAL & $\mathbf{4 0}$ & $\mathbf{5}$ & - & $\mathbf{1 2}$ & $\mathbf{5 7}$ & $\mathbf{1 0 0}$ \\
\hline$\%$ & 70,2 & 8,8 & - & 21,0 & 100 & - \\
\hline
\end{tabular}

Fonte: dados da pesquisa.

Quanto aos artigos publicados em espanhol, a revista Ciência da Informação continua sendo a mais hospitaleira, enquanto a Informação $\mathbb{E}$ Sociedade: Estudos, antes totalmente fechada à publicação de artigos em outros idiomas que não o português, só a partir de 2000 publica o primeiro artigo em espanhol. Embora esteja um pouco mais receptiva aos artigos estrangeiros, tendo publicado apenas cinco trabalhos, limita-se a divulgar trabalhos de autores provenientes da Espanha, em particular da Universidade Carlos III, não demonstrando nenhum laço de integração com os países latino-americanos.

A revista Transinformação publicou 21,0\% dos artigos, mas em situação bastante atípica, pois quase todos foram divulgados em um só ano, como se demonstra na tabela 2. Provavelmente em virtude da reestruturação da revista, que a partir de 2003 passa a ter periodicidade quadrimestral e se enquadra nos padrões nacionais e internacionais de publicação científica, agregando ao conselho editorial membros europeus, em particular dois pesquisadores espanhóis.

Em geral, a maioria desses artigos $(59,7 \%)$ é de autoria individual, pertencente a uma diversidade de instituições com poucos trabalhos e cujos autores publicaram apenas um artigo, salvo algumas exceções, com no máximo quatro artigos.

Um autor da Universidade Carlos III da Espanha que atuou em universidades brasileiras mediante convênio Cátedra, da Unesco, financiado pelo $\mathrm{CNPq}$, publicou dois artigos na Ciência da Informação e dois na Informação Eु Sociedade: Estudos, um em colaboração com colegas de sua universidade e outro com um brasileiro que fez doutorado na Espanha. Esse autor também publicou em colaboração com brasileiros, inclusive artigos em português, portanto contribuiu tanto com a produção do conhecimento endógeno, quanto com a divulgação de artigos em espanhol.

Mais seis autores publicaram dois artigos, dos quais cinco publicaram na mesma revista (um da Universidade Autônoma de Madri, um da Universidade de Granada, um da Universidade do Chile e dois da Universidade de La Habana,) e um autor da Universidade Nacional de La Plata, Argentina, publicou em duas revistas: Ciência da Informação e Transinforamção. À exceção do que só publicou na Informação $\mathbb{E}$ Sociedade: Estudos, observa-se que os autores com mais de um artigo publicaram pelo menos um em colaboração, donde se infere que os autores que publicam em colaboração produzem mais.

Além de escassas, as co-autorias têm origem na mesma instituição, sendo 14,0\% dos artigos em colaboração de dois autores; $14,0 \%$, de três e $12,3 \%$, com mais de três, sendo uns com quatro, outros com cinco e um artigo com oito autores.

Esses resultados estão em conformidade tanto com os dados de Mueller e Pecegueiro (2001), que apontam a predominância da autoria individual ou única nos anos 90 , quanto com a análise de 32 anos da revista Ciência da Informação, que apresenta os percentuais de autoria única $(77,2 \%)$ no período de 1972-1979 e $(56,4 \%)$ no período de 1990-1999. E, embora no período de 2000-2004, a tendência seja de produção em co-autoria $(68,3 \%)$, no geral, mesmo entre os autores mais produtivos predomina a autoria única (individual) e o acentuado número de autores que escreveram uma só vez. No entanto, contradiz a afirmativa de Price (1976, p. 55) citado por Pinheiro, Bräsche e Burnier (2005) de que a incidência de trabalhos científicos em colaboração tem aumentado de forma vertiginosa e que, se for mantido esse ritmo, ao redor de 1980 desapareceriam os artigos de autoria única.

A falta de trabalhos em co-autoria e a distribuição dos temas, observados nos títulos dos artigos e nas palavras-chave, que vão do livro à Web, não evidenciam nenhuma tendência para determinada linha ou grupo de pesquisa em particular. 


\section{ORIGEM GEOGRÁFICA E INSTITUCIONAL DOS ARTIGOS EM ESPANHOL}

Os autores dos artigos publicados na íntegra em espanhol provêm de instituições de diferentes países, predominantemente de universidades, com exceção de um organismo internacional e dois institutos nacionais, um tecnológico e outro de documentação. A Espanha predomina com 21 artigos; Argentina aparece com 12; de Cuba há 6; do México 5; do Chile, 3; do Paraguai, Uruguai, Estados Unidos e Brasil, 2 cada; Venezuela, um; existe ainda um de origem não identificada.

Tais dados reiteram os resultados do balanço de 10 anos da produção científica de biblioteconomia e documentação, do período de 1992 a 2001, no qual Jiménez-Contreras (2002) afirma que, no âmbito geopolítico latino-americano, a Espanha lidera a produção, seguida do Brasil em segundo lugar, e do México em terceiro. Também no período de 1991 a 2000, segundo MoyaAnegón e Herrero-Solana (2002), entre os países ibero-americanos o Brasil é o segundo maior produtor na área de biblioteconomia e documentação, perdendo apenas para a Espanha.

A Espanha, na revista Ciência da Informação, de acordo com Pinheiro, Bräscher e Burnier (2005), ocupa o 39 lugar em produtividade de autores, perdendo apenas para os Estados Unidos e Brasil.

Os dois artigos em espanhol de autores brasileiros resultaram de trabalhos desenvolvidos em universidades espanholas: um autor é da Universidade do Estado de Santa Catarina (Udesc) com doutorado pela Universidade Complutense de Madrid, e outro é da Universidade Estadual de Londrina (UEL), doutorando na Universidade de Alcalá de Henares.

Os dois provenientes dos Estados Unidos são de autores hispanoparlantes, um da Organización Panamericana de la Salud e outro da Universidade da Califórnia. Observa-se que nem sempre a nacionalidade do autor é obrigatoriamente a mesma da instituição à qual está vinculado.

A Espanha, com maior número de artigos, 36,8\% do total, o Brasil, com 3,5\%, e os Estados Unidos, com 3,5\%, juntos são responsáveis por $43,8 \%$, o que significa que $56,2 \%$ dos artigos provêm dos demais países latino-americanos e do Caribe, destacando-se a Argentina com 21\%.

Comparando-se aos dados do estudo anterior ao Mercosul (1983 a 1990), quando Espanha e Venezuela foram os países com maior numero de artigos, 30,7\% cada um, e no período do Mercosul (1991 a 1998), o México publicou 27,2\% e Espanha 22,7\%, sendo os mais produtivos, pode-se afirmar que os artigos provenientes da Espanha vêm predominando ao longo dos anos e, ao contrário do que se esperava, as intenções de integração do Mercosul têm surtido pouco efeito na área.
Mais da metade $(57,61 \%)$ das citações foram feitas a trabalhos em português, o que se justifica, até certo ponto, por ser este o idioma nato das revistas, pois contrariamente à idéia de globalização, pela facilidade de acesso ao conhecimento endógeno e domínio lingüístico, pesquisadores tendem a citar a literatura endógena. Em segundo lugar, com 32,56\%, vem o inglês, idioma oficial da comunicação científica.

A média de citação por artigo é de 21,4, embora haja ocorrido artigo com pouquíssima ou nenhuma citação. $\mathrm{O}$ artigo com menor número de referência foi um divulgado em francês, que só teve uma na língua original e outra em inglês. E o com maior número foi um artigo em espanhol com 216 citações.

\section{CITAÇÕES}

No período analisado, as quatro revistas publicaram 805 artigos que produziram 17.270 citações em vários idiomas, conforme tabela 3 . Observa-se que na tabela se usam os percentuais com duas casas decimais para expressar a ocorrência de idiomas que, embora em índices insignificantes, não poderiam deixar de ser registrados.

\section{Tabela 3}

\begin{tabular}{l|r|r|r|r|r|c}
\hline \multicolumn{7}{l}{ Idioma das citações por revista } \\
\hline \multicolumn{1}{c|}{ IDIOMA } & RE. Inf. & Inf.\&Soc. & Perspect. & Transinf. & TOTAL & $\%$ \\
\hline Português & 3.494 & 2.394 & 1.950 & 2.111 & 9.949 & 57,61 \\
Inglês & 3.000 & 708 & 1.000 & 915 & 5.623 & 32,56 \\
Espanhol & 630 & 180 & 93 & 332 & 1.235 & 7,15 \\
Francês & 183 & 88 & 59 & 59 & 389 & 2,25 \\
Italiano & 23 & 14 & - & 4 & 41 & 0,24 \\
Alemão & 12 & 14 & - & - & 26 & 0,15 \\
OutroS & 4 & 3 & - & - & 7 & 0,04 \\
\hline TOTAL & $\mathbf{7 . 3 4 6}$ & $\mathbf{3 . 4 0 1}$ & $\mathbf{3 . 1 0 2}$ & $\mathbf{3 . 4 2 1}$ & $\mathbf{1 7 . 2 7 0}$ & $\mathbf{1 0 0}$ \\
\hline \% & 42,54 & 19,69 & 17,96 & 19,81 & 100 & \\
\hline \multicolumn{7}{|c}{ Fonte: dados da pesquisa } \\
& \multicolumn{7}{c}{ O item Outros inclui: russo, catalão, holandês e tcheco. }
\end{tabular}

As citações em espanhol, objeto desta análise, vêm em terceiro lugar, porém com expressiva baixa no percentual: apenas 7,15\%. Embora goze de posição de destaque em relação aos demais idiomas citados e tenha aumentado o índice em relação ao estudo anterior de Nascimento (1999), que foi de apenas 4,5\%, e em relação às revistas eletrônicas, que, segundo Nascimento (2007), fica em torno de $6 \%$, este resultado leva a inferir que o uso de informação gerada na região está muito aquém do desejado.

Tais dados demonstram que em geral os autores que publicam nas revistas brasileiras usam pouco a literatura em espanhol, que inclui, além da produção científica da Espanha, Cuba, México e demais países da América do Sul e as versões em espanhol de trabalhos divulgados em outros idiomas. $\mathrm{O}$ descaso com essa literatura talvez seja fruto da descrença no conhecimento gerado pelos países hispanófanos, principalmente os sul-americanos, que não fazem parte do mainstrain da ciência mundial, ou ainda pela falta de domínio desse idioma. 
As 1.235 referências em espanhol foram citadas por 281 artigos, com média de 1,5 por artigo, e, embora haja muitos com uma só citação, constatou-se a ocorrência de alguns com 17, 18 e um caso com 45 citações, incidência essa que obviamente ocorreu nos publicados em espanhol. Com exceção do artigo em francês, os demais fizeram citações em espanhol, independentemente do idioma do artigo, embora em proporções menores às feitas pelos artigos em espanhol.

Comparando o percentual de $34,9 \%$ de artigos citantes no atual período, de 1999 a 2006, com os 37\% dos artigos citantes no período de 1983 a 1990, e 67,7\% no período de 1991 a 1998, pode-se afirmar que houve considerável aumento da "presença" de artigos em espanhol nas revistas brasileiras nos oito anos imediatamente posteriores à criação do Mercosul, mas ao longo dos anos o decréscimo foi de quase 50\%.

Observa-se na tabela 4 que, embora em 2006 tenha ocorrido o maior número de artigos citantes (18,7\%), tal índice resulta da considerável produção das quatro revistas, mas não significa que houve crescimento anual ascendente, pois há anos em que o percentual aumenta e em outros diminui. O segundo percentual mais alto (16,4\%) foi em 2003, como decorrência da alta produção de "perspectivas" em ciência da informação com 20 artigos.

A revista Ciência da Informação divulgou 42\% dos artigos citantes, enquanto Perspectivas em Ciência da Informação, com o menor índice de artigos citantes (12,5\%), também foi a menor produtora de citações. Comparando esse resultado com os do estudo anterior, constata-se que antes do Mercosul a revista Ciência da Informação ficou em segundo lugar, com 25,\% dos artigos citantes e $25,5 \%$ das citações, pois naquela época a Revista Biblioteconomia de Brasília era a mais produtiva, com 36,6\% dos artigos citantes e 32,0\% das citações em espanhol. Já no período do Mercosul, Ciência da Informação fica em primeiro lugar, com 51,3\% dos artigos citantes e 61,3\% das citações.

Tabela 4

\section{Artigos citantes por ano}

\begin{tabular}{c|r|r|r|r|r|r}
\hline \multirow{2}{*}{ ANO } & \multicolumn{4}{|c|}{ REVISTAS } & \multirow{2}{*}{ TOTAL } & \multirow{2}{*}{$\%$} \\
\cline { 2 - 5 } & Ci. Inf. & Inf. Soc. & Perspect. & Transinf. & & \multicolumn{1}{c}{11,4} \\
\hline 1999 & 14 & 6 & 2 & 10 & 32 & 11,4 \\
2000 & 14 & 7 & 3 & 5 & 29 & 10,3 \\
2001 & 9 & 4 & 2 & 11 & 26 & 9,3 \\
2002 & 14 & 5 & 3 & 4 & 26 & 9,3 \\
2003 & 11 & 6 & 9 & 20 & 46 & 16,4 \\
2004 & 24 & 1 & 8 & 9 & 42 & 14,9 \\
2005 & 12 & 5 & 3 & 7 & 27 & 9.7 \\
2006 & 20 & 15 & 5 & 13 & 53 & 18,7 \\
\hline TOTAL & $\mathbf{1 1 8}$ & $\mathbf{4 9}$ & $\mathbf{3 5}$ & $\mathbf{7 9}$ & $\mathbf{2 8 1}$ & $\mathbf{1 0 0}$ \\
\hline$\%$ & 42,0 & 17,4 & 12,5 & 28,1 & 100 & \\
\hline
\end{tabular}

Fonte: dados da pesquisa.

Chama-se a atenção para Informação $\mathfrak{E}$ Sociedade, que no período do Mercosul estava iniciando sua publicação com uma abrangência mais local e apresentava apenas 9,6\% dos artigos citantes e 8,7\% das citações, ficando sempre nos últimos lugares; mas agora quase dobra esses percentuais e coloca-se em terceiro, embora siga publicando poucos artigos em espanhol, o que significa que os autores brasileiros dessa revista estão usando mais a literatura hispanófona como base para a produção do conhecimento.

Das 1.235 citações em espanhol, 22,4\% e 20,7\% ocorreram respectivamente em 2003 e 2004, não se podendo afirmar que o crescimento do número de citações está diretamente relacionado ao número de artigos citantes. Comparando-se os dados das tabelas 4 e 5, observa-se que 2006 foi o ano com maior índice de artigos citantes, mas fica em terceiro lugar, com $19,2 \%$ das citações.

Comparando-se os índices de artigos divulgados em espanhol, artigos citantes e citações, não se encontra uma correlação absoluta dos percentuais, mas observa-se que os índices mais altos ocorrem em 2003, 2004 e 2006.

Tabela 5

Citações em espanhol por ano em que foram citadas

\begin{tabular}{|c|c|c|c|c|c|c|}
\hline \multirow{2}{*}{ ANO } & \multicolumn{4}{|c|}{ REVISTAS } & \multirow{2}{*}{ TOTAL } & \multirow[b]{2}{*}{$\%$} \\
\hline & Ci.Inf. & Inf.Soc. & Perspect. & Transinf. & & \\
\hline 1999 & 23 & 18 & 4 & 49 & 94 & 7,6 \\
\hline 2000 & 63 & 16 & 7 & 17 & 103 & 8,3 \\
\hline 2001 & 15 & 7 & 11 & 29 & 62 & 5,0 \\
\hline 2002 & 58 & 25 & 7 & 5 & 95 & 7,7 \\
\hline 2003 & 90 & 11 & 23 & 153 & 277 & 22,4 \\
\hline 2004 & 203 & 20 & 12 & 20 & 255 & 20,7 \\
\hline 2005 & 61 & 20 & 3 & 28 & 112 & 9,1 \\
\hline 2006 & 117 & 63 & 26 & 31 & 237 & 19,2 \\
\hline TOTAL & 630 & 180 & 93 & 332 & 1235 & 100 \\
\hline$\%$ & 51,0 & 14,6 & 7,5 & 26,9 & 100 & \\
\hline
\end{tabular}

\section{TIPO E IDADE DOS DOCUMENTOS CITADOS EM ESPANHOL}

Conforme tabela 6, o tipo de documento mais citado foi artigo de periódico, com 37,3\%, e o menor índice encontrado foi $0,5 \%$ de teses. Apesar de tratar de temas atuais e relevantes e mesmo considerando as facilidades de acesso ao banco de teses do Ibict, as teses são pouco utilizadas talvez em razão da relativa dificuldade de acesso físico, pois, muitas vezes, restringem-se às instituições de origem, universidades, principalmente as estrangeiras, que oferecem o doutorado e são suas depositárias.

Embora as citações a artigo estejam aquém do índice determinado por Price (1970) de que 80\% das citações efetuadas na literatura periódica são de artigos, esse percentual está bem mais acima do encontrado no período de 1991 a 1998, quando a ocorrência foi de $31 \%$ de citações a livros e apenas 25\% a artigos, índice que 
se aproxima de encontrado por Nascimento (2000) nas revistas eletrônicas, que foi de 29,8\%. O aumento de citações de artigos pode ser uma conseqüência do aumento do número de títulos de revistas divulgadas nos últimos anos e da facilidade de acesso às publicações via rede mundial de computadores.

Com percentual de $24,0 \%$, o item Outros inclui uma miscelânea de documentos dispersos em vários artigos que não se justifica especificar separadamente. São eles os seguintes: capítulos de livro, dicionários, boletins, folhetos, anuários, sites, documentos eletrônicos, textos de Internet, slides, documentos governamentais, atas, manuais, leis, decretos, artigos da constituição, programas de governo, catálogos, guias de indexação, enciclopédias, anuários estatísticos, projetos, almanaques, matérias de jornal, teses de licenciatura, trabalhos de conclusão de curso (TCC) etc.

\section{Tabela 6}

\section{Tipo de documentos citados}

\begin{tabular}{|c|c|c|c|c|c|c|c|}
\hline \multirow{2}{*}{ REVISTAS } & \multicolumn{6}{|c|}{ TIPOS DE DOCUMENTOS } & \multirow[b]{2}{*}{ TOTAL } \\
\hline & Artigo & Livro & Evento & Relatório & Tese & Outros & \\
\hline Ci. Inf. & 232 & 179 & 48 & 9 & 5 & 157 & 630 \\
\hline Inf. \& Soc. & 114 & 36 & 6 & 2 & 2 & 20 & 180 \\
\hline Perspect. & 44 & 17 & 16 & 1 & - & 15 & 93 \\
\hline Transinfor. & 71 & 109 & 46 & 1 & 1 & 104 & 332 \\
\hline TOTAL & 461 & 341 & 116 & 13 & 8 & 296 & 1.235 \\
\hline$\%$ & 37,3 & 27,6 & 9,4 & 1,1 & 0,6 & 24,0 & \\
\hline
\end{tabular}

Os tipos de documentos citados em espanhol também foram agrupados por data de publicação em relação ao ano de divulgação da revista citante para identificar a diferença em anos, ou seja, a idade das citações, e determinar a vida média da literatura citada. Para Burton e Kleber (1960), a vida média é o tempo durante o qual metade da literatura citada foi publicada, isto é, a idade em que ocorrem 50\% do total das citações.

Enquanto a vida média dos artigos citados foi de três anos e meio, a dos livros foi de oito anos, dos trabalhos divulgados em eventos foi de 4 anos; dos relatórios, pouco mais de dois anos; das teses um ano, e de Outros tipos de documentos foi de sete anos.

Apesar da ocorrência de idades bastante elevadas, como citação a artigos com até 60 anos, livros com até 69 , eventos com até 55 , relatórios com no máximo 15 , uma tese com 55 e Outros tipos com até 96 anos, pelo cálculo da vida média se pode inferir que, embora possa haver citação à literatura obsoleta, esses casos isolados, com idades tão avançadas, que ainda seguem sendo citados são trabalhos clássicos para a área. No geral, pode-se afirmar que a literatura em espanhol utilizada como base para o conhecimento endógeno, respeitando as características do tipo de documento citado, é bastante atualizada.

\section{CONSIDERAÇÕES FINAIS}

No mundo globalizado, não há lugar para os monolíngües, e, sem relegar nossa língua nata nem exagerar no patriotismo, deve-se reconhecer que menosprezar o uso do espanhol como meio de divulgação e intercâmbio de informação científica é fechar-se nas fronteiras da ilha lusófona e desperdiçar a oportunidade de acesso à grande massa de informações e conhecimentos divulgados nesse idioma e, acima de tudo, perder a oportunidade de dar maior visibilidade à produção do conhecimento gerado e ou divulgado em território nacional, tendo em vista que o espanhol é uma das línguas mais faladas no mundo, além de idioma oficial de muitas instituições internacionais.

A maioria dos artigos em espanhol é de autoria individual, e, pela diversidade de instituições de origem dos autores, deduzse que as iniciativas isoladas podem ser resultantes mais dos contatos pessoais do que institucionais. As poucas co-autorias sempre são intra-institucionais, e a diversidade e fragmentação dos temas abordados não explicitam a existência de linhas ou grupos de pesquisa trabalhando em cooperação na região.

Embora se reconheça que em outros âmbitos as iniciativas de cooperação e integração na região tenham dado certo, os baixos percentuais da "presença" da literatura hispanófona de biblioteconomia, documentação e ciência da informação nas revistas brasileiras da área evidenciam certa frustração dos ideais de estreitar laços culturais e científicos e intercâmbio de informações com vistas à integração no Mercosul.

O predomínio da produção de artigos provenientes da Espanha ao longo dos anos é, em parte, conseqüência da vinda de professores estrangeiros para universidades brasileiras e resultado da ida de brasileiros para cursar o doutorado naquele país ou de contatos de pesquisadores brasileiros com as universidades espanholas.

Os percentuais comprovam a preferência pelo uso de fontes publicadas em inglês e o pouco uso da produção do conhecimento gerado na região, ao contrário do que prega Campos (1999), de que a América Latina plural nos oferece grande diversidade de fontes de informação e que resgatar a literatura produzida na região nos ajudaria a ter uma visão da realidade com base em nossos autores.

Portanto, além de ampliar a oportunidade de acesso a um leque maior de conhecimentos mais consentâneos com nossa latinidade, reduzindo a dependência de fontes produzidas em países do mainstrain que divergem da nossa realidade, divulgar e usar a literatura hispanófona fortaleceria os laços de integração e daria maior credibilidade e visibilidade à produção do conhecimento latino-americano. 
Contrariando o que se esperava, apesar de despertar as revistas brasileiras para maior receptividade à publicação de artigos em espanhol, as intenções de integração do Mercosul não surtiram efeito nos autores da área de biblioteconomia, que não demonstraram nenhuma iniciativa de trabalhos em cooperação entre a comunidade de pesquisadores latinoamericanos, e pouco usaram a literatura hispanófona como base para a produção do conhecimento endógeno.

Muitas questões restam sem resposta e poderão ser tema de investigações futuras: apesar da proximidade geográfica e dos pregados incentivos e políticas integracionalistas, por que os pesquisadores brasileiros autores da área de biblioteconomia, documentação e ciência da informação não quebram as barreiras etnocêntricas e lingüísticas? Por falta de domínio do espanhol? Por dificuldade de contatos e indiferença da comunidade científica dos demais países latino-americanos? Pela inexistência ou falta de credibilidade no conhecimento gerado fora do mainstrain,? Ou por seguir apenas em uma posição de admirador, indiferente ao trabalho e à comunidade científica da região?

Artigo recebido em 06/12/2007

e aceito para publicação em 16/05/2008

\section{REFERÊNCIAS}

ARENAS, Judith Licea de, et. al. Una visión bibliométrica de la investigacónen biblioteccología y ciencias de la información de América Latina y el Caribe. Revista Española de Documentación Científica, v. 23, n. 1, p. 45-53, 2000. Disponível em: <www.cindoc.csic.es $>$. Acesso em: 11 maio 2005.

AZEVEDO, Fernando. A cultura científica. In: . A cultura brasileira. 4. ed. rev. e amp. Brasília: Editora Universidade de Brasília, 1963. Cap. IV, p. 367-431.

BURTON, R. E; KLEBER, R. The half-life of some scientific and technical literatures. American Documentation, v. 11, n. 1. p. 18-22, Jan. 1960.

CAMPOS, E. M. La infodiversidad, los bloques regionales y la cooperación. Transinformação, Campinas, v. 11, n. 2, p. 135-144, maio/ago. 1999.

CASTRO, C. A. O periódico no campo da biblioteconomia no Brasil: possibilidades para um fazer historiográfico. Transinformação, Campinas, v. 18, n. 1, p. 9-15, jan./ abr. 2006.

COORDENAÇÃO DE APERFEIÇOAMENTO DE PESSOAL DE NÍVEL SU. PERIOR - CAPES. Classificação de periódicos, anais revistas e jornais. Brasília, [s.d.]. Disponível em: < http://qualis.capes.gov.br/webqualis/>. Acesso em: 10 jul. 2007.

FERREIRO ALAÈZ, L. Bibliometria: análisis bivariente. Madrid: Eypasa, 1993. 480 p.

JIMENEZ-CONTRERAS. E. La aportación española a la producción científica internacional en biblioteconomía y documentación: balance de diez años (1992-2001). Biblioteconomia y Documentación, n. 9, dic. 2002. Disponível em < $<$ www.ub.es/bid $>$. Acesso em: 30 jun. 2007.

LE COADIC, Yves-François. A ciência da informação. Trad. De Maria Yeda F. S. de Figueiras Gomes. Brasília: Briquet de Lemos/Livros, 1996. 119 p.
LÓPEZ PIÑERO, J. M. L; NAVARRO, V.; PORTEL, A. E. La revolución científica. Madrid: Historia 16, 1989. 218 p.

MENEZES, C. Alcances, logros y pasos futuros de los programas de comunicación e información en Mercosur. IN: TAILLER LATINOAMERICANO: RECURSOS Y POSIBILIDDES, 2., 2004. Anales electrónicos... Disponível em: < www.icsep.info/ programa/docs/en/Resumen >. Acesso em: 30 jun. 2007.

MIRANDA, A. Produção científica na ciência d informação. Ciência da Informação, Brasília, v. 27, n. 1, p. 5-6, 1998

MOREL, Regina L.M. Ciência e estado: a política científica no Brasil. São Paulo: T. A. Queiroz, 1979.172 p.

MOYA-ANEGÓN, F.; HERRERO-SOLANA, V. Visibilidad internacional de la producción científica iberoamericana en biblioteconomía y documentación (1991. 2000). Ciência da Informação, Brasília, v. 31, n. p. 54-65, set./dez. 2002.

MUÑOZ, G. Sesión inaugural. In: Taller LATINOAMERICANO RECURSOS Y POSIBILIDDES DE LA PUBLICACIÓN ELECTRÓNICA, 2., 2004. Anales electrónicos... Disponível em: $<$ http://www.icsep.info/level.php?lang=es\&chann el=presentation $>$. Acesso em: 30 jun. 2007.

MUELLER, S. P. M. et. al. Disseminação da pesquisa em ciência da informação e Biblioteconomia no Brasil. Ciência da Informação, Brasília, v. 25, n. 3, p. 337-351, set./dez. 1996.

PERCEGUIERO, C. M. de A. M. O periódico ciência da informação na década de 90: um retrato da área refletido em seus artigos. Ciência da Informação, Brasília, v. 30, n. 2 p. 47-63, maio/ago. 2001.

NASCIMENTO, M. de J. Presença da literatura de língua espanhola, utilizada como base a produção do conhecimento endógeno, na área de biblioteconomia e ciência da informação após o Mercosul. Florianópolis: UDESC, 1999. 87 p.

; BOSO, A. K. Presença da literatura hispanófona da área de biblioteconomia documentação e ciência da informação nas revistas brasileiras on-line Florianópolis: UDESC, 2007. 21 p.

NEVES, C. E. B.; MOROSINI. M. C. Cooperação universitária no Mercosul. Em aberto 68. Disponível em: < http://www.inep.gov.br/download/cibec/1995/periodicos/em aberto 68.doc $>$. Acesso em: 14 jun. 2007.

PINHEIRO, L. V. R.; BRÄSCHER, M.; BURNIER, S. Ciência da informação: 32 anos (1972-2004) no caminho da história e horizontes de um periódico científico brasileiro. Ciência da Informação, Brasília, v. 34, n. 3, p. 25-80, 2005.

PINTO, A. L.; RODRÍGUEZ BARQUÍN, B. A.; MOREIRO GONZÁLEZ, J. A. Análisis de citación de la revista Ciência da Informação del Ibict. Ciência da Informação, Brasília, v. 35, n. 3, p. 153-165, 2006.

PRITCHARD, Alan. Statistical bibliography or bibliometics?. Joumal Documentation, v. 24, n. 4, p. 348-349, dic. 1969.

SABATINI, R. A história da revistas científicas. Correio Popular, Campinas, p. 3 ,

12 mar. 1999

SCHWARTZMAN, S. Formação da comunidade científica no Brasil. São Paulo: Ed. Nacional; Rio de Janeiro: FNEP, 1979. 479 p.

SENA CORREA, E. N. El Mercosur hacia la sociedad de la información. Ciência da Informação, Brasília, v. 32, n. 2, p. 37-46, maio/ago. 2003.

URBIZÁGASTEGUI ALVARADO, R. Las revistas de bibliotecología y ciencias de la información en América Latina. Transinformação, v. 11, n. 2, p. 153-172, 1999. 